\title{
RESENHA: \\ ASSISTENTES SOCIAIS E RELIGIÃO (PEDRO SIMÕES)
}

SIMÕES, Pedro. Assistentes Sociais e Religião: um estudo Brasil/Inglaterra. São Paulo: Cortez, 2005.

MAGALHÃES, Vinicius Pinheiro de PROSS - UFS - Sergipe/ Brasil ${ }^{1}$

Pedro Simões é assistente social e mestre formado pela Universidade Federal do Rio de Janeiro. Seu livro é resultado de sua tese de doutorado em Sociologia defendida no Instituto Universitário de Pesquisa do Rio de Janeiro - IUPERJ da Universidade Cândido Mendes - UCAM com período sanduíche na Middlesex University (Inglaterra). Seu trabalho recebeu o segundo lugar do Prêmio Melhor Tese do Ano (2004). O autor discute as seguintes temáticas como intelectual e pesquisador: religião, assistência social, assistência religiosa e sistema socioeducativo.

Simões introduz sua obra afirmando ser documentada a influência religiosa na constituição do que se chamou de Serviço Social. Entretanto, um problema que ele coloca com propriedade a este respeito, é o trato da religião apenas no que se refere à gênese da profissão. Pedro Simões problematiza essa questão e propõe uma investigação sobre a atualidade da mediação religiosa na prática profissional; à revelia dos teóricos que relegaram o elemento religioso ao lugar restrito da gênese do Serviço Social. Nesse sentido, o objetivo do autor de “Assistentes Sociais e Religião” é “[...] dar relevo ao que consider[a] uma importante mediação na prática assistencial" (SIMÕES, 2005, p. 20).

Esse objetivo é o que ainda torna a presente discussão temática um elemento relevante para a categoria, tendo em vista a continuidade do recalque do trato da Religião no âmbito do Serviço Social - utilizo o termo recalque para resgatar a noção de "recalque da subjetividade" no âmbito do Serviço Social trabalhado por Vasconcelos (2010), que abarca a questão da religião. Sobre essa omissão José Paulo Netto afirma

\footnotetext{
${ }^{1}$ Mestrando e Bolsista CAPES/DS pelo Programa de Pós-graduação em Serviço Social da Universidade Federal de Sergipe - PROSS. Membro do Grupo de Estudos e Pesquisas em Fundamentos, Formação em Serviço Social e Políticas Sociais - GEPSSO-UFS. Áreas de discussão: Serviço Social, trabalho, formação profissional, Saúde Mental e Religiosidade/Espiritualidade. e-mail: viniciuspmaga@gmail.com
} 
em declaração publicada na contracapa do livro: "A contribuição deste jovem pesquisador seguramente contribuirá [...] para recolocar na agenda dos debates profissionais [...] vetores ideais que, incidindo sobre a ação dos assistentes sociais, estiveram [...] desterrados para uma zona de sombras".

Simões organiza sua obra em três partes (Dos fundamentos; Motivações e distinções; e Vínculos e nexos na teoria e na prática) e a divide em seis capítulos.

Na primeira parte do livro (Dos fundamentos) estão inclusos os capítulos um e dois. No primeiro capítulo o autor propõe discutir a capilaridade da religião, na sua relação com a assistência social, tanto no Brasil e Inglaterra como noutras regiões do mundo. No exemplo da Inglaterra, o autor infere que desde a Lei dos Pobres até o início do século XX a religião vem influenciando a prática assistencial. As instituições assistenciais de caráter religioso precedem àquelas que propunham maior laicidade. A trajetória do Serviço Social neste país se traduziu em confluências, no que se refere a um objetivo comum, das instituições públicas com as privadas - estas com características filantrópicas e religiosas - que em última instância dificultou o entendimento da assistência social como profissão. Mesmo com as influências da sociologia e da psicanálise na década de 1980, as características morais - de influência puritana e vitoriana, de caráter protestante - eram elementos indispensáveis para estabelecer o perfil dos assistentes sociais. No que se refere ao Brasil, o autor não diverge muito da exposição do exemplo inglês. As protoformas do Serviço Social brasileiro surgem não de uma preocupação com a racionalização da assistência social, mas de uma atuação ativa do laicato católico, que passa a intervir de forma missionária no âmbito da "questão social". As experiências de secularização com o ingresso da fenomenologia e do positivismo não modificaram a base prática dos profissionais, que ainda era neotomista. A hegemonia marxista que se desenvolveu no seio da profissão a partir da década de 1980 - crítica do segmento moralista-conservador da categoria - foi mediada pela Teologia da Libertação (católica); mostrando que muitos teóricos críticos do conservadorismo tiveram acesso a Marx a partir das experiências progressistas no âmbito da Igreja Católica. Trazendo considerações mais gerais - agora não mais restritas ao Brasil e Inglaterra - o autor afirma que a religião, no que se refere ao surgimento do Serviço Social, tem profunda ligação com a criação das primeiras escolas européias, com a origem do Serviço Social norte-americano, e com a capilarização das 
primeiras escolas da América Latina. Pedro Simões, concluindo o primeiro capítulo, expõe de forma clara como a profissão é marcada por uma intensa indeterminação sobre sua expertise em diversos países onde a profissão se ramificou, podendo citar os continentes europeu; americano; africano e asiático; o que a aproxima muito do trabalho voluntário/religioso.

No segundo capítulo, ainda na primeira parte do livro (Dos fundamentos), o autor pretende expor os fundamentos religiosos da Assistência Social. Primeiro, demonstra a relação de afinidade entre o catolicismo, o protestantismo e a Assistência Social. Simões afirma que a assistência social católica e protestante estão associadas à ética da salvação. A ética da salvação católica supervaloriza as obras como um pressuposto para a salvação; o que justifica o trabalho e ação social dessa tradição. Já a ética da salvação protestante, baseadas no calvinismo, valoriza uma ascese intramundana que busca a "glorificação de Deus" na vida cotidiana, e a riqueza material é um sinal da aprovação de Deus. A generosidade, nesse sentido, se estabelece como uma forma de assistência social protestante "[...] quanto mais se dividem e se partilham os bens de Deus, mais crescem as graças de Deus sobre aquele que age de forma desprendida" (SIMÕES, 2005, p. 59). O autor sugere outras afinidades quando propõe a confluência da assistência social também com o espiritismo. A assistência social nessa tradição está muito relacionada ao lugar da alteridade, na medida em que valoriza a doutrina do amor ao próximo; o que influencia inúmeros trabalhos sócio-assistenciais dirigidos por esta tradição. Em seguida, Simões afirma ainda que algumas profissões não são escolhidas por características mercadológicas, mas pelo caráter valorativo destas. É o caso do Serviço Social, muito associado aos elementos do cuidado, do altruísmo, da ajuda e da convicção. Além de demonstrar ainda que os valores religiosos, transmitidos através da educação familiar, atuam como formadores de conduta; o que determina, em última instância, inclusive a escolha da profissão.

Na segunda parte do livro (capítulos 3 e 4 - Motivações e distinções) - parte que possui os elementos mais significativos para a constituição da originalidade do trabalho - o autor expõe os resultados de seu estudo feito com 42 assistentes sociais (17 brasileiros e 25 ingleses) sobre a importância da religião para a escolha profissional, além de complementar estes resultados com outra pesquisa realizada com calouros do curso de Serviço Social - o estudo também contou com alunos da Pedagogia, Ciências 
Sociais, Comunicação, Administração e Ciências contábeis - no Brasil (ano de 2001) e na Inglaterra (ano de 2003), a fim de verificar se "[...] o ideário da ajuda social [...] poderia ser também identificado entre os alunos" (SIMÕES, 2005, p. 22).

O capítulo três revela elementos que contribuem para o entendimento da chamada "vocação profissional do assistente social". A maior parte dos assistentes sociais entrevistados (brasileiros e ingleses), afirmaram ter tido família religiosa e uma formação religiosa, com participação em catecismo; culto/missa; grupo jovem; colégio religioso; e trabalho beneficente. $\mathrm{O}$ estudo também mostrou que o conhecimento prévio da profissão, a partir de contato com profissionais (no caso brasileiro) e de experiências com o trabalho voluntário (no caso inglês) fortaleceram uma auto-identificação vocacional com a profissão. As motivações e expectativas do trabalho para os profissionais entrevistados se relacionaram com a ideia de ajuda. No caso brasileiro a noção de ajuda era verticalizada, isto é, a regência era sempre do profissional (tutela). No caso inglês a noção de ajuda era horizontalizada, no sentido de promoção de um empoderamento meritocrático. O fato é que ficou clara a relação entre elementos da religião como fatores motivacionais para a escolha do Serviço Social como profissão, confirmando a declaração de Iamamoto (2013) que afirma ser a busca pelo curso algo relacionado a "vantagens simbólicas" que extrapolam os elementos econômicos de ascensão social.

No capítulo quatro o autor expôs os resultados de uma pesquisa survey realizada com 398 estudantes (178 do Brasil e 220 da Inglaterra), que revelou que o curso de Serviço Social - tanto no caso brasileiro como no inglês - se distingue dos demais (Comunicação, Administração e Ciências contábeis) pelo fator “ajuda” ser elemento de motivação para a escolha da profissão, além de abarcar valores muito associados à religião: justiça social, igualdade, solidariedade, comunitarismo e amor ao próximo. Essa distinção com os demais cursos também se manifestou com a constatação de maior participação, entre estudantes de Serviço Social, em trabalhos voluntários e beneficentes. Ademais, a maior parte dos estudantes do Serviço Social era cristã (os católicos são maioria no Brasil e os protestantes na Inglaterra), tinha pais religiosos, e participava ativamente de instituições religiosas. "Os alunos agregam ao curso valores como amor ao próximo, justiça social, igualdade [...] que, sobretudo, se afirma como um desejo de ajuda. [...] Pode-se inferir que o sentido de ajuda social é o elemento 
central atribuído para a escolha da profissão e a ele estão agregados valores religiosos" (SIMÕES, 2005, p. 126).

Na parte 3 do livro (Vínculos e nexos na teoria e na prática) constam os capítulos 5 e 6 . No capítulo cinco Pedro Simões pretende identificar a relevância da religião para os assistentes sociais e autores do Serviço Social brasileiros e ingleses. À semelhança dos dados quantitativos dos estudantes, constatou-se que a maior parte dos assistentes sociais entrevistados é religiosa. No Brasil o catolicismo é a religião de maior aderência dos profissionais do Serviço Social, seguidos do Kardecismo e dos sem-religião ${ }^{2}$. O autor afirma que a incidência de protestantes abaixo desses segmentos se deve ao fato do Kardecismo ter maior afinidade e semelhança com as práticas assistenciais católicas. Os profissionais entrevistados também revelaram participação ativa nas instituições religiosas e nos trabalhos voluntários; o que é significativo dada a pouca incidência de participação nos movimentos sociais e partidos políticos. Na literatura inglesa sobre o Serviço Social a temática da religião se manifesta desde a década de 1950 e perdura até o século XX, ainda que de forma restrita. Muitos dos autores ingleses que se dedicaram a este tema não escondem a relação subjetiva que têm com a religião. Nessa literatura há uma separação terminológica de Religião (termo mais relacionado a mediação institucional) e Espiritualidade (termo referente a experiências supra-institucionais), que se configuram como necessidades dos indivíduos demandatários dos serviços sociais. Na literatura brasileira, Simões disserta sobre o período que vai da origem da profissão até a década de 1970, onde a categoria lança mão de bases fenomenológicas e positivistas para a assistência sem perder de vista elementos do neotomismo. Depois, problematiza a teoria produzida nas décadas seguintes (1970-1980). A religião é retratada de forma mais crítica com o aporte teórico do marxismo, entretanto a característica religiosa da profissão não se perde, pois o ranço religioso se transfigurou numa perspectiva teórica de análise da realidade com características essencialmente religiosas - Trata-se de uma clara crítica ao dogmatismo epistemológico marxista, ou como quer Vasconcelos (2002), ao "imperialismo epistemológico".

No sexto e último capítulo do livro, Simões pretende verificar como os valores

\footnotetext{
2 Pedro Simões (2005) sugere que o marxismo de caráter materialista pode influenciar parte da categoria pela aderência do ateísmo, mas considera que isso é algo que precisa ser estudado de forma aprofundada.
} 
religiosos se materializam na prática profissional da assistência, e quais as características positivas dessa relação na perspectiva dos profissionais entrevistados. $\mathrm{O}$ autor revelou que a literatura, especificamente a inglesa, sugere maior consideração dos elementos culturais e religiosos pelos profissionais da assistência social, na medida em que se constituem como importantes fatores para uma efetiva atuação ética profissional. Como pontos positivos da relação Religião x Assistência Social, Pedro Simões concluiu que essa relação serve para: uma noção de complementaridade entre trabalho religioso/voluntário e profissional, em virtude da falta de clareza da expertise da profissão; essa relação estabelece a fé como um elemento que extrapola o ambiente privado e potencializa o trabalho assistencial; estabelece valores religiosos que reforçam, numa perspectiva ética, a prática profissional; promove um forte senso de imparcialidade, tendo em vista a problematização - por parte dos profissionais - da tensão que existe entre fé e proselitismo; propõe uma abordagem holística de atuação profissional, que considera as dimensões bio-psico-sócio-espirituais; favorece práticas espirituais que potencializam o trabalho sem desresponsabilizar o profissional; e propõe uma ressignificação do trabalho do assistente social, dando relevância aos valores religiosos como o amor, em detrimento das características economicistas do trabalho assalariado. $\mathrm{O}$ autor ainda põe em discussão as principais críticas postas a essa positiva convergência temática (Religião $\mathrm{x}$ assistência social), que resumidamente tratam da problemática da laicidade do Estado e do caráter subjetivo da religião; o que a torna um tema a ser tratado em âmbito privado. Como um contraponto às críticas, Simões expõe propostas que objetivam a incorporação da Religião no processo formativo em Serviço Social, que de forma geral são sugestões que pretendem superar a consideração restrita da relevância da Religião na profissão para práticas concretas como oficinas, disciplinas e debates que efetivamente incorporem esse tema na formação profissional.

Concluído o trabalho, considero que esta obra contribui de forma significativa em três pontos. O primeiro diz respeito ao próprio Serviço Social. Essa discussão temática contribui para expor de forma clara e lúcida os descompassos existentes entre o Projeto ético-político da profissional de base materialista, os valores religiosos dos profissionais assistentes sociais, e a religiosidade dos demandatários das políticas sociais. Uma segunda contribuição desta obra é sua inediticidade no âmbito do Brasil, trazendo ao debate a "mediação religiosa" como um importante elemento para se 
considerar a essencialidade da assistência social. Infelizmente depois de treze anos de sua publicação nenhum outro trabalho de relevo surgiu para contribuir com o debate; o que evidencia a permanência de sua relevância. Um terceiro ponto de contribuição dessa obra refere-se à crise da esquerda no Brasil. A esquerda perdeu a capacidade de dialogar com os símbolos das classes populares e, consequentemente, perdeu lugar para as igrejas na relação com as mesmas; sobretudo de origem pentecostal e neopentecostal. Essa obra não trata especificamente deste debate, mas infere sobre a incapacidade da esquerda (a exemplo do Projeto Profissional do Serviço Social) de incorporar a Religião como elemento relevante para mediar uma relação de aproximação com as classes populares.

\section{Referências}

IAMAMOTO, Marilda Villela. Renovação e conservadorismo no Serviço Social. Ensaios críticos.12 ed. São Paulo: Cortez, 2013.

SIMÕES, Pedro. Assistentes Sociais e Religião: um estudo Brasil/Inglaterra. São Paulo: Cortez, 2005.

VASCONCELOS, Eduardo Mourão. Complexidade e Pesquisa Interdisciplinar: epistemologia e metodologia operativa. 2 ed. Petrópolis/RJ: Vozes, 2002.

Da hiperpsicologização normatizadora ao recalcamento da subjetividade: notas históricas sobre Serviço Social, subjetividade e saúde mental no Brasil e no Rio de Janeiro. In: (org.). Saúde Mental e Serviço Social: o desafio da subjetividade e da interdisciplinaridade. 5 ed. São Paulo: Cortez, 2010. p. 181-214. 